\title{
Cholinesterase-inhibiting Potential and Anti-BACE1 Activities of Edible Leaves of Selected Thai Local Plants ${ }^{\dagger}$
}

\author{
Uthaiwan SUTTISANSANEE ${ }^{*}$ and Kalyarat KRUAWAN
}

Institute of Nutrition, Mahidol University, Phutthamonthon, Nakhon Pathom 73170, Thailand

('Corresponding author's e-mail: uthaiwan.sut@mahidol.ac.th)

Received: 31 March 2018, Revised: 19 June 2018, Accepted: 26 August 2018

\begin{abstract}
Alzhiemer's disease (AD) is common amongst the elderly and is associated with decline in brain functions in terms of memory and cognitive loss. The causes of the disease may occur through loss of presynaptic markers of cholinergic system and deposition of amyloid fibrils in the brain. Cholinesterases (ChEs) including acetylcholinesterase (AChE) and butyrylcholinesterase (BChE) are the key enzymes controlling degradation of neurotransmitters, acetylcholines (AChs), in cholinergic hypothesis. Whereas overproduction of $\beta$-secretase (BACE1) can generate insoluble $\beta$-amyloid peptides. Thus, retardation on enzyme reactions can lead to potential AD prevention. The aim of this research was to investigate in vitro anti-AD activity through key enzymes inhibitions from Thai local plants with edible sour leaves, including Garcinia cowa Roxb., Spondias pinnata (Linn.f.) Kurz, Syzygium gratum (Wight) S.N. Mitra., Tamarind indica L. and Cratoxylum formosum (Jack) Dyer. Leaves were extracted in organic solvents with different polarity index values (ethanol and hexane). As results, all plants possessed different degrees of anti-ChEs activity, in which ethanolic extracts of Spondias pinnata and Tamarind indica exhibited significantly higher ChEs inhibitory activities than Syzygium gratum, Garcinia cowa and Cratoxylum formosum, respectively. Interestingly, most hexane extracts exhibited higher anti-AChE activities than ethanol extracts, while the contrary results were observed in anti-BChE activity. Besides, only Cratoxylum formosum, Garcinia cowa and Tamarind indica extracts possessed anti-BACE1 activity. The information received from this study would be great support of future drug development or nutraceutical agents against $\mathrm{AD}$ occurrence regarding its cholinergic and $\beta$-amyloid formation hypotheses.
\end{abstract}

Keywords: Alzheimer's disease, anti-cholinesterase activity, anti- $\beta$-secretase activity, edible sour leaves, Thai local plants

\section{Introduction}

Alzheimer's disease (AD) is one of the leading neurological disorders, which degrades learning, memory and cognitive functions of nervous system, eventually leaving a person with an inability to perform any self-functions. Even though this disease has been recognized for more than a century, the exact cause of AD remains unclear. Nevertheless, 2 major pathways have been hypothesized and widely investigated, including a loss of presynaptic markers of a cholinergic system and an accumulation of $\beta$ amyloid plaque in the brain [1]. Cholinergic hypothesis is emphasized on degradation of neurotransmitters such as acetylcholine $(\mathrm{ACh})$ and butyrylcholine $(\mathrm{BCh})$ by Cholinesterases $(\mathrm{ChEs})$, including acetylcholinesterase (AChE) and butyrylcholinesterase (BChE), leading to termination of

\footnotetext{
${ }^{\dagger}$ Presented at the International Conference on Biomedical Sciences 2018: March $22^{\text {nd }}-23^{\text {rd }}, 2018$
} 
http://wjst.wu.ac.th

impulse transmission at cholinergic synapsis. In AD patients, the concentrations of ACh and choline are found to be rapidly declined, whereas AChE is excessively increased, causing nerve cell dysfunction [2]. Thus, decreased cholinergic activities and neurotransmitters in the central nervous system (CNS) are the markers of declined brain memory and cognitive function [2]. For AD medical treatment, 4 commercially available AD drugs have been developed according to this hypothesis and approved as tacrine, donepezil, rivastigmine and galatamine. Most of these drugs function as ChEs inhibitors, which are proven to be effective in delaying the symptoms of AD. However, a definite cure has yet to be found. Another hypothesis on $\beta$-amyloid formation is emphasized on $\beta$-secretase (also known as $\beta$-site amyloid precursor protein cleaving enzyme1 or BACE1), the enzyme that hydrolyzes amyloid precursor protein (APP) into toxic $\beta$-amyloid peptide and eventually amyloid plaques. The plaques can stimulate innate immune response, leading to cell inflammatory, cell abnormality, and eventually cell death [3]. It was previously found that that inhibition of BACE1 activity in mice could lead to less $\beta$-amyloid production [4].

Currently, the investigation in natural products that can act as nutraceutical foods is of an interesting matter to promote health benefits. Medicinal plants possess advanced benefits in relevant to the belief of safe and dependable consumption as well as lower price than synthesized drug with several adverse effects. Five local plants in Thailand including Garcinia cowa Roxb., Spondias pinnata (Linn.f.) Kurz, Syzygium gratum (Wight) S.N. Mitra., Tamarind indica L. and Cratoxylum formosum (Jack) Dyer produce sour leaves, which can be either cooked in many main dishes or consumed as fresh leaves for traditional medicine. Various parts of these plants have been intensively studied in term of isolation and purification of bioactive compounds with a wide range of biochemical and pharmacological properties i.e., antioxidant, anti-microbial activities, cytotoxic effect toward cancer cell lines and anti-inflammatory [5-10]. Interestingly, even though there is no related research on anti-AD property of these plants up until now, the bioactive compounds that had been previously identified in these plants could inhibit ChEs and BACE1 reactions [11-13]. Some even had a record on their CNS depressant effect [14,15]. However, limited information on the anti-AD property of the crude extract of these plants is available. Therefore, the objective of this study is to investigate potential anti-AD activities of these 5 local plants regarding the cholinergic hypothesis and $\beta$-amyloid formation through inhibition of the key enzymes (ChEs and BACE1). The information received from this investigation will provide beneficial knowledge on anti-AD activity of Thai edible plants with sour leaves, which can be further developed into functional food or even neutraceuticals against AD.

\section{Materials and methods}

\section{Sample preparation and extraction}

Fresh leaves from G. cowa, S. pinnata, S. gratum, T. indica and C. formosum were selected and sorting into 3 groups $(n=3)$. Leaves were washed with deionized water before drying in a lyophilizer (a Heto Powerdry PL9000 from Heto Lab Equipment, Allerod, Denmark). The dry samples were ground to fine powder by a cyclotex sample mill (series 1903 with 200 - 240V and 50/60 Hz from FOSS, Höganäs, Sweden) before being stored at $-20{ }^{\circ} \mathrm{C}$. The moisture content of fresh and freeze-dried samples was analyzed by Association of Official Analytical Chemists (AOAC) official method (930.15, AOAC, 2005).

The crude extract was prepared according to the protocols reported by Muangpracha et al. [16]. Dry plant powder ( $4 \mathrm{~g}$ dry weight) was mixed with either ethanol or hexane $(400 \mathrm{~mL})$ and extracted for $6 \mathrm{~h}$ using a Soxhlet extractor at $40{ }^{\circ} \mathrm{C}$. The extracts were lyophilized and then dissolved in DMSO (50 $\mathrm{mg} / \mathrm{mL}$ ) before storing at $-20^{\circ} \mathrm{C}$.

\section{Determination of cholinesterase inhibitory activities}

Anti-ChEs activity was measured utilizing adapted method of Jung et al. [17] with some modifications as indicated in Kukreja et al. [18]. The enzymatic activity was monitored at a wavelength of $412 \mathrm{~nm}$ using a microplate reader (BioTek Instruments, Inc., Winooski, VT) and a Gen5 data analysis software. The inhibitory activity of each plant extract was performed in triplicate and calculated as percentage of inhibition as followed. 
http://wjst.wu.ac.th

$\%$ inhibition $=\left(1-\frac{B-b}{A-a}\right) \times 100$

where $A$ is an initial velocity of the control reaction with enzyme (control), $a$ is an initial velocity of the control reaction without enzyme (control blank), $B$ is an initial velocity of the enzyme reaction with extract and $b$ is an initial velocity of the reaction with the extract but without enzyme (sample blank). The efficiency of the plant extracts against ChEs was determined by the half maximal inhibitory concentration $\left(\mathrm{IC}_{50}\right)$, which was analyzed from a dose-response plot of the extracts versus percentage of inhibition using a GraphPad Prism (version 5.00) for Windows (GraphPad Software, Inc., La Jolla, CA).

\section{Determination of anti-BACE1 activity}

Inhibitory activity against BACE1 was determined using a $\beta$-secretase (BACE1) Activity Detection Kit (Fluorescent) from Sigma-Aldrich (St. Louis, MO, USA). The inhibitory assay consisted of the plant extracts $(0.4 \mathrm{mg} / \mathrm{mL})$, BACE1 enzyme $(0.3$ unit $/ \mu \mathrm{L})$ and BACE1 substrate $(50 \mu \mathrm{M})$ in fluorescent assay buffer. All reactions were monitored at an excitation wavelength of $320 \mathrm{~nm}$ and an emission wavelength of $405 \mathrm{~nm}$ using the microplate reader. The inhibitory activity was calculated as percentage of inhibition as followed.

$\%$ inhibition $=\left(1-\frac{B-b}{A-a}\right) \times 100$

where $A$ is an absorbance of the control reaction with enzyme (control), $a$ is an absorbance of the control reaction without enzyme (control blank), $B$ is an absorbance of the enzyme reaction with the extract and $b$ is an absorbance of the reaction with the extract but without enzyme (sample blank).

\section{Statistical analysis}

All experiments were carried out in triplicate. The data were expressed as mean \pm standard deviation (SD). One way analysis of variance (ANOVA) followed by Duncan's Multiple Range Test using the SPSS 16.0 statistical package was performed to determine the significant differences between values $(p<0.05)$.

\section{Results and discussion}

Five local plants with edible sour leaves including G. cowa, S. pinnata, S. gratum, T. indica and $C$. formosum were investigated regarding their biological functions against AD through cholinergic hypothesis and $\beta$-amyloid formation. Since degradation of neurotransmitters, ATCh and BTCh, by cholinesterases, AChE and BChE, respectively, can cause AD occurrence, inhibition of these enzymes provides alternative pathway of AD treatment and prevention. As results, the ethanolic extract from $S$. pinnata exhibited the highest AChE inhibitory activity with the $\mathrm{IC}_{50}$ of $47.6 \mu \mathrm{g} / \mathrm{mL}$, followed by $T$. indica (the $\mathrm{IC}_{50}$ of $97.8 \mu \mathrm{g} / \mathrm{mL}$ ), while $S$. gratum, $G$. cowa and $C$. formosum only exhibited marginal inhibitory activities (the $\mathrm{IC}_{50}>400 \mu \mathrm{g} / \mathrm{mL}$ ) (Figure 1A and Figure 2A). Similarly, the trend of inhibitory action on $\mathrm{BChE}$ suggested that $S$. pinnata inactivated the enzyme with the lowest $\mathrm{IC}_{50}$ of $27.3 \mu \mathrm{g} / \mathrm{mL}$, while $T$. indica exhibited the $\mathrm{IC}_{50}$ of $101.5 \mu \mathrm{g} / \mathrm{mL}$ (Figure 1B and Figure 2B). On the other hand, S. gratum, G. cowa and $C$. formosum exhibited lower BChE inhibitory activities $\left(\mathrm{IC}_{50}>300 \mu \mathrm{g} / \mathrm{mL}\right)$. Thus, the $\mathrm{AChE}$ and $\mathrm{BChE}$ inhibitory activities of ethanolic extracts suggested that $S$. pinnata leaves contains the most effective anti-ChEs agents, followed by those of $T$. indica, S. gratum, G. cowa and C. formosum, respectively. These inhibitory activities were also compared to eserine, a positive control, in which it was found that under the same extraction concentration of all plants, the ethanolic extract of S. pinnata provided the most efficient anti-AD agent through cholinergic hypothesis. Its inhibitory activities using ethanolic extract $(0.1 \mathrm{mg} / \mathrm{mL})$ were equivalent to 0.53 and $2.51 \mu \mathrm{M}$ of eserine for $\mathrm{AChE}$ and $\mathrm{BChE}$ reactions, respectively, while the $\mathrm{IC}_{50}$ of eserine estimated under the same assay condition was $0.41 \mu \mathrm{M}$ for $\mathrm{AChE}$ reaction and $1.43 \mu \mathrm{M}$ for $\mathrm{BChE}$ reaction. 
A

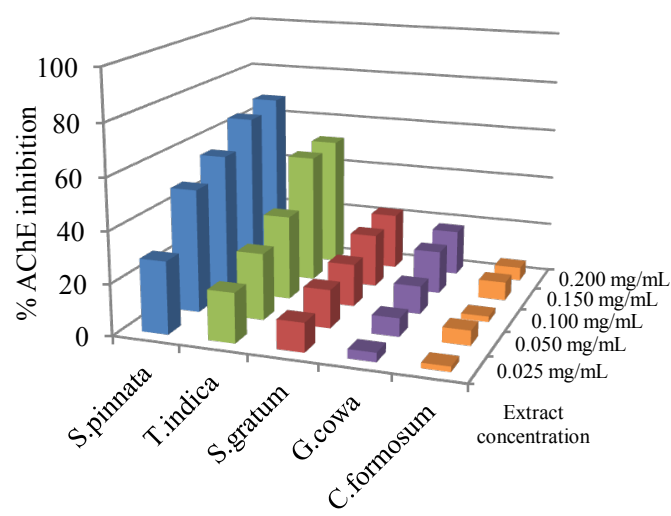

B

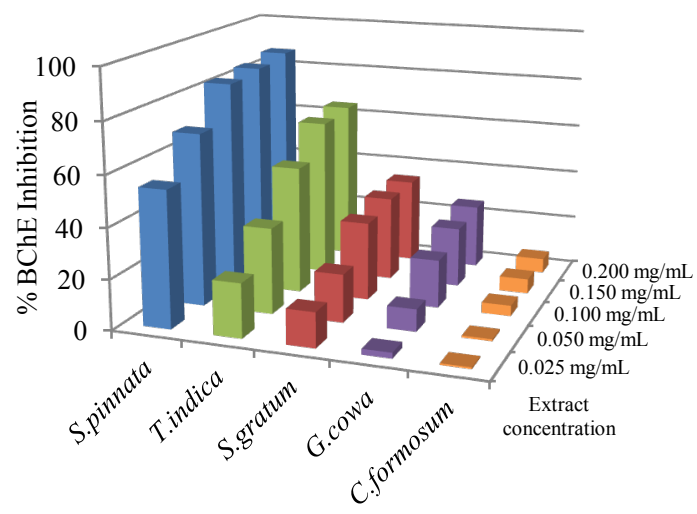

Figure 1 The cholinesterase inhibitory activities including (A) AChE (10 ng) and (B) BChE (50 ng) inhibitory activities of the ethanolic extracts $(0.025-0.20 \mathrm{mg} / \mathrm{mL})$ from leaves of $G$. cowa, S. pinnata, S. gratum, T. indica and C. formosum using ATCh $(0.08 \mathrm{mM})$ and BTCh $(0.1 \mathrm{mM})$, respectively, as the substrates.

A

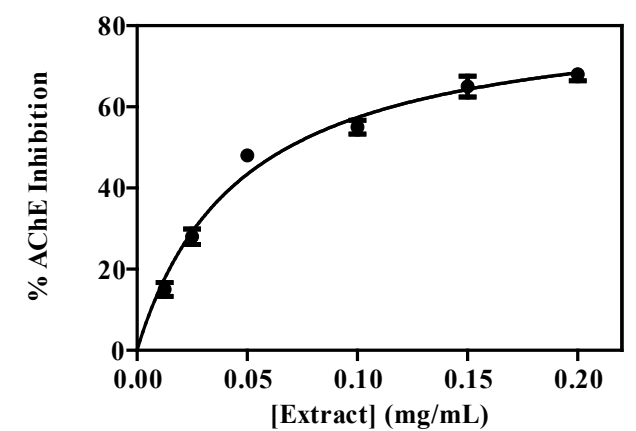

B

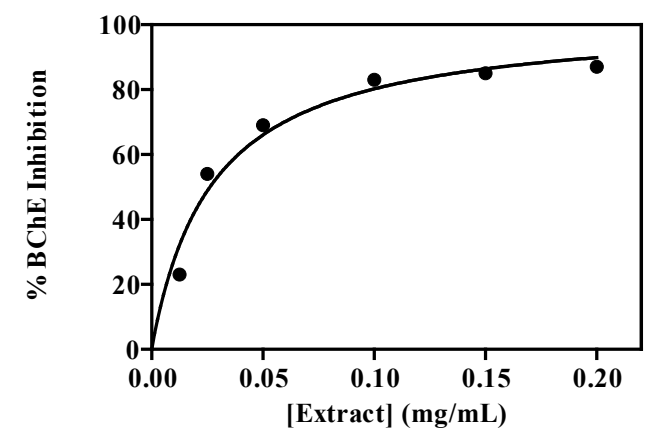

Figure 2 The dose-response plot (percentages of inhibition versus ethanolic extraction concentrations) for determination of the half maximal inhibitory concentration $\left(\mathrm{IC}_{50}\right)$ of $S$. pinnata against (A) AChE (10 ng) and $(\mathrm{B}) \mathrm{BChE}(50 \mathrm{ng})$ utilizing ATCh $(0.08 \mathrm{mM})$ and BTCh $(0.1 \mathrm{mM})$, respectively, as the substrates.

When comparing extraction solvents, ethanol and hexane, it was found that hexane extracts exhibited significantly higher AChE inhibitory activities than their ethanolic counterparts in exception of $S$. pinnata (Figure 3). On the other hand, ethanolic extracts exhibited significantly higher BChE inhibitory activities than their corresponding hexane extracts in exception of G. cowa and C. formosum extracts (Figure 3). This information suggested that most anti-AChE agents likely contain hydrophobic groups, while most anti-BChE agents likely behave as hydrophilic molecules. Interestingly, BChE inhibitory activities were higher than those of AChE reactions under ethanol extraction system in exception of $C$. formosum extract, while all hexane extracts exhibited higher AChE than BChE inhibitory activities (Figure 3). This phenomenon can be explained by enzyme-substrate structural determination under the hypothesis that these anti-ChE agents can act as competitive inhibitors. In this type of inhibition, the enzyme-inhibitor interactions are occurred within the enzyme catalytic pockets. An acyl (catalytic) pocket of BChE (PDB ID: 1P0I) composes of small aliphatic Leu286 and Val288, which are responsible for catalysis and substrate specificity [19]. Comparing to the acyl pocket of AChE (PDB ID: 5FOQ) that consists of larger Phe295 and Phe297, the substrates binding site in the catalytic pocket of 
http://wjst.wu.ac.th

$\mathrm{BChE}$ is less selective than the smaller active site of AChE [20,21]. Therefore, BChE can accepted wide range of inhibitor due to its larger catalytic pocket, leading to higher anti-BChE activity as being observed in ethanolic extracts. However, all hexane extracts exhibited higher AChE than BChE inhibitory activities, suggesting that hydropholic anti-ChE agents in these plants are likely small compounds and are very specific to AChE. Since AChE possesses smaller catalytic pocket, ChE inhibitors can form tight interactions with the enzyme, leading to the more effective anti-AChE agents, which can be observed as higher anti-AChE activity than anti-BChE activity. In other modes of inhibition such as non-competitive and uncompetitive manners, the inhibitors can bind to the enzyme or enzyme-substrate complex in the binding site other than the active site. It is also possible that these anti-ChE agents (most likely hydrophobic anti-AChE agents and hydrophilic ant-BChE agents) can, as well, inhibit the enzyme through enzyme-inhibitor interactions outside the enzyme active site. These hypotheses can be further confirmed using enzyme kinetics or X-ray crystallographic determination.

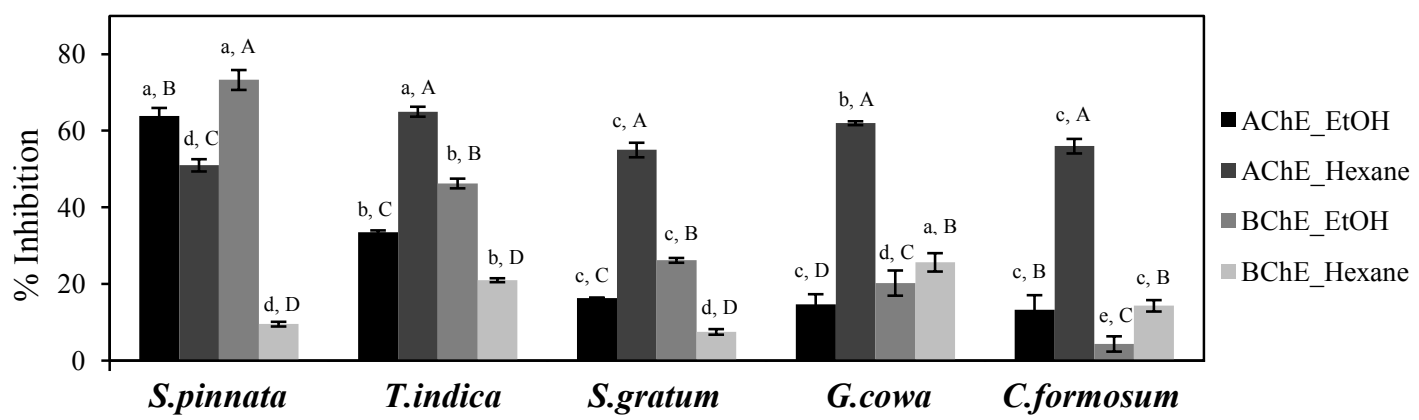

Figure 3 The comparison of cholinesterase inhibitory activities, AChE (10 ng) and BChE (50 ng), of ethanolic and hexane extracts $(0.1 \mathrm{mg} / \mathrm{mL})$ from leaves of G. cowa, S. pinnata, S. gratum, T. indica and C. formosum using ATCh $(0.08 \mathrm{mM})$ and BTCh $(0.1 \mathrm{mM})$, respectively, as the substrates. The lower letters showed statistically significant difference of each assay group (different plants in the same extraction solvent and the same enzyme assay) and the capital letters represented statistically significant difference in each plant sample (same plant extracted under different extraction solvents and enzyme assays) at $p$ value $<0.05$ using one-way ANOVA and Duncan's Multiple Range Test.

Several nutritional compositions from $S$. pinnata were previously discovered and isolated [22]. Even though no biological property of these isolated compounds was investigated, the crude extract from this plant possesses various medicinal properties, including function against dysentery, antibacterial activities, central nerve system (CNS) depressant effect, diuretic and laxative activity and anti-tubercular properties [5-8]. Besides, this plant is a potential source of natural antioxidant with no significant toxicity being observed [23]. Among all five plants investigated in our experiments, S. pinnata leaves exhibited the highest content of total phenolics [16]. Although phytochemicals had been identified from many parts of $S$. pinnata [5,6], no report is currently available for its leaves. However, phenolics in Spondias tuberosa Arr. Cam. and Spondias mombin L. leaves had been reported as ellagic acid, rutin and quercetin [24]. Ellagic acid exhibited the $\mathrm{IC}_{50}$ of $13.79 \mu \mathrm{g} / \mathrm{mL}$ against $\mathrm{AChE}$ [11] and $16.0 \%$ of $\mathrm{BChE}$ inhibition at the concentration of $250 \mu \mathrm{g} / \mathrm{mL}$ [12]. Interestingly, quercetin and its glycosylated form (rutin) are more effective inhibitors despite of being detected in lower amount than ellagic acid. It was found that quercetin exhibited the $\mathrm{IC}_{50}$ of $0.055 \mu \mathrm{g} / \mathrm{mL}$ against $\mathrm{AChE}$ and $0.061 \mu \mathrm{g} / \mathrm{mL}$ against $\mathrm{BChE}$, while rutin exhibited the $\mathrm{IC}_{50}$ of $0.128 \mu \mathrm{g} / \mathrm{mL}$ against $\mathrm{AChE}$ and $0.176 \mu \mathrm{g} / \mathrm{mL}$ against $\mathrm{BChE}$ [13]. However, other bioactive compounds might, as well, present in $S$. pinnata leaves, which causes high inhibitory activities as being observed in this experiment. Since the ethanolic extracts of $S$. pinnata exhibited higher ChEs inhibitory activities than its hexane extracts, its bioactive compounds with anti-ChE property might likely possess hydrophilic functional groups such as pheolics. However, the hypothesis on this aspect should be 
http://wjst.wu.ac.th

confirmed by identification of bioactive compounds from $S$. pinnata leaves. Besides, other modes of inhibition (as stated above) should be taken into consideration as well.

The second most effective anti-ChE extract is from $T$. indica leaves. Several parts and biological properties of $T$. indica have been widely investigated with fruit pulp being emphasized (high contents of tartaric acid and reducing sugars) [25]. Young leaves of $T$. indica can sometimes be used as sour ingredient instead of lemon and are found to possess high antioxidant, anthelmintic activity, antiinflammatory, antinociceptive activity and anti-apoptotic hepatoprotective effects $[9,10,25,26]$. As well, whole plant possessed antimicrobial activity, both bacteria and fungi, to solve multidrug resistance microbial infection [27]. The hexane extract of $T$. indica leaves exhibited higher anti-AChE activity than its ethanolic extract, suggesting that anti-AChE agents found in $T$. indica might be small compounds with hydrophobic functional groups. Previous research had been suggested that hexane extract of $T$. indica leaves contained alkaloids [28], which can act as effective anti-AChE agents [29]. However, its ethanolic extract exhibited higher BChE inhibitory activity than its hexane extract, suggesting that $T$. indica leaves might contain hydrophilic anti-BChE agents. It was previously reported that methanolic extract of $T$. indica leaves contained catechin, epicatechin and quercetin [30]. Quercetin was reported to be more effective towards ChEs than catechin and epicatechin, respectively [31]. Catechin was found to exhibit anti-AChE activity with the $\mathrm{IC}_{50}$ of $36 \mu \mathrm{g} / \mathrm{mL}$, while its anti-BChE activity was present as the $\mathrm{IC}_{50}$ of 20 $\mu \mathrm{g} / \mathrm{mL}$ [32]. Thus, higher BChE than AChE inhibitions in ethanolic extract observed in our experiment might be due to the effectiveness of these flavonoids. However, other bioactive compounds that have not yet been identified should also be taken into consideration. From these information, it could be concluded that $T$. indica leaves might contain hydrophobic agents (such as alkaloids) with higher AChE specificity than hydrophilic agents. However, it might contain hydrophilic agents (such as phenolics) with higher BChE specificity than hydrophobic agents. Under the hypothesis that these anti-ChE agents can act as competitive inhibitors, the different sizes of the enzyme catalytic pockets can determine the size of inhibitors. Since BChE possesses larger catalytic pocket than that of AChE, it can be hypothesized that anti-ChE (hydrophilic) agents found in this ethanolic extract might be large bioactive compounds. These compounds can fit appropriately into the larger active site of $\mathrm{BChE}$, but might be incapable of entering the smaller active site of AChE. This hypothesis leads to tight binding between inhibitor and BChE and, thus, resulting in higher $\mathrm{BChE}$ inhibition than $\mathrm{AChE}$ inhibition. On the other hand, anti-ChE (hydrophobic) agents found in hexane extract might be small copounds, since hexane extract exhibited higher anti-AChE than anti-BChE activities. However, other mode of inhibitory actions, in which inhibitors can bind to the inhibitory binding site other than the active site of the enzyme, should be taken into consideration as well. In this case, quantity of inhibitor will determine the effectiveness of inhibition rather than enzyme specificity.

Interestingly, even though the crude extracts from $C$. formosum and $G$. cowa exhibited only trace cholinesterase inhibitory activities, both ethanolic and hexane extracts from these plants provided high inhibitory activities against BACE1, the key enzyme that control the formation of $\beta$-amyloid plague (Table 1). The ethanolic extract of $C$. formosum exhibited the highest BACE1 inhibitory activity (77.5 $\%$ ), followed by those of $G$. cowa and $T$. indica, respectively, while no inhibitory activity was detected in $S$. pinnata and $S$. gratum extracts. On the other hand, hexane extract of $G$. cowa exhibited the highest anti-BACE1 activity ( $72.5 \%$ ), followed by those of $C$. formosum and $T$. indica, respectively, while no inhibitory activity was observed in $S$. pinnata and $S$. gratum extracts.

Currently, drugs discovery of BACE1 inhibitors were designed base on chemical interactions between enzyme and inhibitor. The BACE1 inhibitors can be divided into 2 groups as early substratebased BACE1 inhibitors and non-peptidic BACE1 inhibitors. In the early substrate-based BACE1 inhibitors (ESBIs), the inhibitors are designed base on a transition-state analogue, which can strongly interact with the active site of BACE1 aspartic protease, thus inhibiting the enzyme activity. In the nonpeptidic BACE1 inhibitors (NPBIs), any NPBIs have been designed and synthesized using the peptidomimetic inhibitors as references and a structure-based drug design (SBDD) computational approach. Therefore, other than phytochemicals, plants with high protein/peptide content are likely able to exhibit BACE1 activity better than the ones with low protein/peptide content. Besides, other modes of inhibition, in which the inhibitors can bind to the enzyme or enzyme-substrate complex outside the 
http://wjst.wu.ac.th

enzyme active site, can, as well, retard BACE1 activity. Some flavonoid derivatives such as polymethoxyflavones and bioflavonoids were reported to act as non-competitive inhibitors toward BACE1 [33].

Table 1 The inhibitory activity of BACE1, the key enzyme that controls the formation of $\beta$-amyloid plague, using plant extracts with ethanol and hexane solvents.

\begin{tabular}{lcc}
\hline \multirow{2}{*}{$*$ *Samples } & \multicolumn{2}{c}{$\%$ BACE1 Inhibition } \\
\cline { 2 - 3 } & EtOH extracts & Hexane extracts \\
\hline C.formosum & $77.5 \pm 0.8$ & $60.5 \pm 1.4$ \\
G.cowa & $17.5 \pm 1.2$ & $72.5 \pm 2.7$ \\
T.indica & $14.9 \pm 1.6$ & $5.3 \pm 1.4$ \\
Sp.pinnata & $\mathrm{ND}$ & $\mathrm{ND}$ \\
Sy.gratum & $\mathrm{ND}$ & $\mathrm{ND}$ \\
\hline
\end{tabular}

*The final concentration of the plant extract $=2 \mathrm{mg} / \mathrm{mL}$

All analytical data were mean values of three independent samples $(n=3) \pm$ standard deviation $(\mathrm{SD})$.

$\mathrm{ND}=$ not detected

The ethanolic extracts from $C$. formosum leaves with the highest BACE1 inhibitory activity might contain anti-BACE1 agents, in this case, as bioactive phytochemicals. Even though protein/peptide can act as effective BACE1 inhibitors, the extraction process (high temperature of Soxhlet extraction for $6 \mathrm{~h}$ ) might aggregate those macromolecules. There is no previous report on anti-BACE1 activity of $C$. formosum; however, it was found that this plant could delay amyloid- $\beta$-induced paralysis using AD Caenorhabditis elegans model [14]. Likewise, there is no report on anti- $\beta$-amyloid property of $G$. cowa; however, G. gracilis leaves had been previously reported regarding its neuroprotective effect [15]. The isolated compound, apigenin-8- $C$ - $\alpha$-L-rhamnopyranosyl- $(1 \rightarrow 2)-\beta$-D-glucopyranoside, from $G$. gracilis leaves could protect P19-derived neuronal cells from serum deprivation induced oxidative stress [15]. Without any further information, $C$. formosum and $G$. cowa leaves potentially possess neuroprotective effect through retardation of $\beta$-amyloid formation.

\section{Conclusions}

Medicinal plants or green medicines are an important therapeutic alternative pathway for treatment and prevention of various ailments. As reported here, all of the edible plants that produce sour leaves including $G$. cowa, $S$. pinnata, $S$. gratum, $T$. indica and $C$. formosum possess medical properties toward anti-AD occurrence, cholinergic pathway and $\beta$-amyloid formation. Two plants, $S$. pinnata and $T$. indica, provided the potential sources for anti-AD agent though cholinergic hypothesis, while $C$. formosum and G. cowa possibly contain anti-BACE1 agents. Besides, extraction solvents were used to hypothesize polarity of anti-ChE agents and to determine future applications of these plants.

\section{References}

[1] M Monczor. Diagnosis and treatment of Alzheimer's disease. Curr. Med. Chem. Cent. Nerv. Syst. Agents 2005; 5, 5-13.

[2] RT Bartus. On neurodegenerative diseases, models, and treatment strategies: lessons learned and lessons forgotten a generation following the cholinergic hypothesis. Exp. Neurol. 2000; 163, 495529. 
http://wjst.wu.ac.th

[3] M Citron, TS Diehl, G Gordon, A Biere, P Seubert and DJ Selkoe. Evidence that the 42- and 40amino acid forms of amyloid beta protein are generated from the beta-amyloid precursor protein by different protease activities. Proc. Natl. Acad. Sci. USA 1996; 93, 13170-5.

[4] P Anand and B Singh. Flavonoids as lead compounds modulating the enzyme targets in Alzheimer's disease. Med. Chem. Res. 2013; 22, 3061-75.

[5] B Hazra, S Biswas and N Mandal. Antioxidant and free radical scavenging activity of Spondias pinnata. BMC Complement Altern. Med. 2008; 8, 63-73.

[6] A Muhammad, S Rahman, H Kabir, S Kabir and K Hossain. Antibacterial and cytotoxic activities of Spondias pinnata (Linn. F.) Kurz fruit extract. Indian J. Nat. Prod. Resour. 2011; 2, 265-7.

[7] TT Mai, NN Thu, PG Tien and NV Chuyen. Alpha-glucosidase inhibitory and antioxidant activities of Vietnamese edible plants and their relationships with polyphenol contents. J. Nutr. Sci. Vitaminol. 2007; 53, 267-76.

[8] JP Chalise, K Acharya, N Gurung, RP Bhusal, R Gurung, N Skalko-Basnet and P Basnet. Antioxidant activity and polyphenol content in edible wild fruits from Nepal. Int. J. Food Sci. Nutr. $2010 ; 61,425-32$.

[9] UU Nwodo, GE Obiiyeke, VN Chigor and AI Okoh. Assessment of Tamarindus indica extracts for antibacterial activity. Int. J. Mol. Sci. 2011; 12, 6385-96.

[10] AI Ghoneim and OA Eldahshan. Anti-apoptotic effects of tamarind leaves against ethanol-induced rat liver injury. J. Pharm. Pharmacol. 2012; 64, 430-8.

[11] G Nag and B De. Acetylcholinesterase inhibitory activity of Terminalia chebula, Terminalia bellerica and Emblica officinalis and some phenolic compounds. Int. J. Pharm. Pharm. Sci. 2011; 3, 121-4.

[12] F Ferreres, C Grosso, A Gil-Izquierdo, P Valentão and PB Andrade. Ellagic acid and derivatives from Cochlospermum angolensis Welw. extracts: HPLC-DAD-ESI/MS ${ }^{n}$ profiling, quantification and in vitro anti-depressant, anti-cholinesterase and anti-oxidant activities. Phytochem. Anal. 2013; 24, 534-40.

[13] AO Ademosun, G Oboh, F Bello and PO Ayeni. Antioxidative properties and effect of quercetin and its glycosylated form (rutin) on acetylcholinesterase and butyrylcholinesterase activities. $J$. Evid. Based Complementary Altern. Med. 2016; 21, NP11-NP17.

[14] R Keowkase and N Weerapreeyakul. Cratoxylum formosum extract protects against amyloid-beta toxicity in a Caenorhabditis elegans model of Alzheimer's disease. Planta Med. 2016; 82, 516-23.

[15] C Supasuteekul, W Nonthitipong, S Tadtong, K Likhitwitayawuid, P Tengamnuay and B Sritularak. Antioxidant, DNA damage protective, neuroprotective, and $\alpha$-glucosidase inhibitory activities of a flavonoid glycoside from leaves of Garcinia gracilis. Rev. Bras. Farmacogn. 2016; 26, 312-20.

[16] N Muangpracha, C Thitisantikhun, K Kruawan and C Petchlert. Antimutagenic and antioxidant capacities of some indigenous sour leave plants. In: Proceedings of the $5^{\text {th }}$ Science Research Conference. University of Phayao, Thailand, 2013.

[17] AH Jung, BS Min, T Yokozawa, JH Lee, YS Kim and JS Choi. Anti-Alzheimer and antioxidant activities of Coptidis Rhizoma alkaloids. Biol. Pharm. Bull. 2009; 32, 1433-8.

[18] RK Kukreja, C Sripum, S Charoenkiatkul, W Kriengsinyos and U Suttisansanee. Evaluation of ethanol concentration, temperature, and shaking time of extracted Thai Jasmine rice on cholinesterase enzyme activity. Int. Food Res. J. 2018; 25, 227-33.

[19] Y Nicolet, O Lockridge, P Masson, JC Fontecilla-Camps and F Nachon. Crystal structure of human butyrylcholinesterase and of its complexes with substrate and products. J. Biol. Chem. 2003; 278, 41141-7.

[20] M Bajda, A Więckowska, M Hebda, N Guzior, CA Sotriffer and B Malawska. Structure-based search for new inhibitors of cholinesterases. Int. J. Mol. Sci. 2013; 14, 5608-32.

[21] AN Çokuğraş. Butyrylcholinesterase: Structure and physiological importance. Turk. J. Biochem. 2003; 28, 54-61.

[22] PK Ghosal and S Thakur. Structural features of the acidic polysaccharide of Spondias pinnata gum exudates. Carbohyd. Res. 1981; 98, 75-83 
[23] KP Kumar and VG Sastry. Toxicity studies of ethanolic extract of Spondias pinnata Kurz. in experimental animals. Int. J. Med. Chem. Anal. 2011; 1, 17-22.

[24] ARA da Silva, SM de Morais, MMM Marques, DF de Oliveira, CC Barros, RR de Almeida, ÍGP Vieira and MIF Guedes. Chemical composition, antioxidant and antibacterial activities of two Spondias species from Northeastern Brazil. Pharm. Biol. 2012; 50, 740-6.

[25] KF Azman, Z Amom, A Azlan, NM Esa, RM Ali, ZM Shah and KKA Kadir. Antiobesity effect of Tamarindus indica L. pulp aqueous extract in high-fat diet-induced obese rats. J. Nat. Med. 2012; 66, 333-42.

[26] SS Bhadoriya, V Mishra, S Raut, A Ganeshpurkar and SK Jain. Anti-inflammatory and antinociceptive activities of a hydroethanolic extract of Tamarindus indica leaves. Sci. Pharm. 2012; 80, 685-700.

[27] R Dabur, A Gupta, TK Mandal, DD Singh, V Bajpai, AM Gurav and GS Lavekar. Antimicrobial activity of some Indian medicinal plants. Afr. J. Trad. CAM 2007; 4, 313-8.

[28] OA Ushie, PA Egwaikhide and BD Longbab. Phytochemical screening and antimicrobial activity of Tamarindus indica. Int. J. Tradit. Compl. Med. 2016; 1, 10-7.

[29] F Moraga, E Hormazábal, H Venthur, A Quiroz and A Mutis. Alkaloids discovery as natural acetylcholinesterase inhibitors, from nature to molecular docking. Rev. Farmacol. Chile. 2016; 9, 16-25.

[30] N Razali, SM Junit, S Abdul-Muthalib, S Subramaniam and AA Aziz. Effects of various solvents on the extraction of antioxidant phenolics from the leaves, seeds, veins and skins of Tamarindus indica L. Food Chem. 2012; 131, 441-8.

[31] D Szwajgier. Anticholinesterase activities of selected polyphenols: A short report. Polish J. Food Nutr. Sci. 2013; 64, 59-64.

[32] N Suganthy and KP Devi. In vitro antioxidant and anti-cholinesterase activities of Rhizophora mucronata. Pharm. Biol. 2016; 54, 118-29.

[33] K Youn, Y Yu, J Lee, WS Jeong, CT Ho and M Jun. Polymethoxyflavones: Novel $\beta$-secretase (BACE1) inhibitors from citrus peels. Nutrients 2017; 9, 973-85. 